\title{
Experimental and numerical analysis of a beam made of adhesively bonded tailor-made blanks
}

\author{
Alessandro Monaco $•$ Jos Sinke $\cdot$ Rinze Benedictus
}

Received: 10 June 2008 / Accepted: 28 November 2008 / Published online: 16 December 2008

(C) The Author(s) 2008. This article is published with open access at Springerlink.com

\begin{abstract}
For aircraft structures, it is clear that the design and the selection of materials play an important role in the performance of the aircraft. The production costs are also important. The concept of tailor-made blanks (TMBs) is based on the use of dedicated blanks, made of different alloys and/or thickness in order to satisfy different demands such as an increase, if necessary, of local strength, stiffness, and damage tolerance. This paper describes the results of a study to assess the potential weight and cost savings of using TMBs in a typical aerospace structure. A bonded structure representing the floor beam of an aircraft has been selected, analyzed, and tested to validate the numerical and analytical predictions made with MATLAB and finite-element method. The results show weight reduction of $12 \%$ and $37 \%$ for two studied configurations, compared to the reference beam.
\end{abstract}

Keywords Tailor-made blanks · Adhesive bonding · FEM modeling $\cdot$ Safety factor $\cdot$ Failure

$t_{\mathrm{I}, \text { II }} \quad$ Thickness in a TMB, mm

$t_{\mathrm{s}} \quad$ Thickness of the section beam, mm

$t \quad$ Thickness of the blank, mm

$\varepsilon_{0} \quad$ True strain, dimensionless

$R \quad$ Bend radius of the middle fiber, $\mathrm{mm}$

$R_{\mathrm{i}, \mathrm{f}} \quad$ Bend radius before spring back, after spring back, mm

$\alpha_{\mathrm{i}, \mathrm{f}} \quad$ Bend angle before spring back, after spring back, ${ }^{\circ}$

$f \quad$ Length of the beam flange, $\mathrm{mm}$

A. Monaco $(\bowtie) \cdot J$. Sinke $\cdot$ R. Benedictus

Faculty of Aerospace Engineering,

Section of Aerospace Materials and Structures,

Delft University of Technology,

Kluyverweg 1,

Delft 2629 HS, The Netherlands

e-mail: alexmo11@hotmail.com $h \quad$ Height of the beam, mm

$l \quad$ Length of the beam, $\mathrm{mm}$

$n \quad$ Safety or reverse factor, dimensionless

$n_{\mathrm{s}} \quad$ Calculated safety factor, dimensionless

$S \quad$ ABAQUS principal stress, V. Mises, MPa

$S_{33} \quad$ ABAQUS principal stress in $z$-direction, $\mathrm{MPa}$

$\varepsilon_{z} \quad$ True strain in $z$-direction, dimensionless

$E_{33} \quad$ ABAQUS true strain in $z$-direction, dimensionless

$\sigma_{\text {eq }} \quad$ Von Mises stress, MPa

$\sigma_{\mathrm{y}} \quad$ Yield stress, $\mathrm{MPa}$

$\sigma_{\mathrm{s}} \quad$ Calculated Von Mises stress, $\mathrm{MPa}$

$\sigma_{z} \quad$ Principal stress in $z$-direction, $\mathrm{MPa}$

$M_{1,2,3} \quad$ Selected materials

$M_{x, y} \quad$ Bending moment in $x, y$-direction, $\mathrm{N}^{*} \mathrm{~m}$

$\mathrm{N} \quad$ Applied force on the beam, $\mathrm{N}$

$I_{x x, y y} \quad$ Second moment of inertia in $x, y$-direction, $\mathrm{mm}^{-4}$

$x, y, z \quad$ Principal directions

$q \quad$ Shear flows, $\mathrm{MPa} / \mathrm{mm}$

$\tau_{x y} \quad$ Shear stresses, MPa

\section{Introduction}

This paper describes a preliminary study on the applicability of the tailor-made blank (TMB) concept for the aircraft industry. The study is focused on a floor beam in the fuselage of a medium-sized aircraft. The selected TMB concept for the beam is an adhesively bonded blank, which is bent to the right dimensions. Testing and analysis should prove whether this concept is viable for the selected structural element.

The TMB concept is already an accepted concept in the automotive industry, in particular for steel parts. The first production parts for the automotive industry were made in 
1985 [1, 2], although the first test articles were from an earlier date (1967- [1]). The delay was caused by the lack of suitable welding technique, which was overcome by the introduction of the laser beam welding. Since the mid1980s, the importance and applications of tailor-welded blanks (TWB) increased rapidly. According to the press release [3] of a material supplier, about $15 \%$ of the body structure of a car is made of TWB parts, which will increase to $25-30 \%$ in the next $5-10$ years.

The TWB are typical for the automotive: it matches very well with the laser beam welding technique. Since 2003, also, aluminum TWB parts are introduced in the automotive industry [4]. Aluminum sheets are welded by laser beam welding or friction stir welding [5]. However, the TWB concept, though by far the most advanced, is not the only concept for TMB. Alternatives are tailored blanks made by adhesive bonding [6] as discussed in this study and tailor-made blanks made by machining [7], i.e., that the thickness of a (thick) sheet is reduced locally before the forming operation. Since the literature on the latter type of TMB is scarce, the state of the art on some relevant aspects is reviewed by using the information on TWB.

The first aspect is the tensile properties of TMB along and perpendicular to the joint and or thickness step. A number of articles describe the strength of weld lines in TWB (e.g., for SFW weld in aluminum alloys [8, 9]). The properties of welds depend on the material properties of the parent materials and the loading direction. For a TMB made by adhesive bonding [6], test results show that when the load is parallel to the doubler edge the failure and other properties depend on the parent materials. In case of testing perpendicular to the thickness, the failure mode depends on the thickness ratio and the adhesive strength; the latter may fail by delamination. The experimental results have been confirmed by numerical analysis. In this study, the doubler edge of the TMB will mainly be loaded in parallel direction.

The formability of an adhesively bonded TMB can also be viewed in two directions. For TWB, the formability is often reduced by the reduction in formability of the weld line $[10,11]$. In forming perpendicular to the weld line, the thickness ratio reduces the formability [12, 13]. For the adhesively bonded TMB, the formability parallel to the edge of the doubler is dominated by the parent materials. In transverse direction, however, the thickness effect will play a role [12]. Since the object of study is a simple beam, the formability of this part is not tested to its limits: the flanges of the beams are bent by simple air bending. The bend radius during bending is matched with the thickness of the parent materials but well above the minimum bend radius.

The spring back that results from the forming process has not been investigated much due to more important topics like the strain distributions and the fact that spring back is not that relevant for in-plane deformations. Only a few literature sources are found of which Zhou's [14] is the most relevant for this study. In the forming of the TMB beam, the thickness ratio will cause different spring-back angles. By choosing the right combination of radius and bend angle, the TMB beam can be manufactured within the required tolerances.

The last aspect is the failure of the TMB. Since the TMB is transformed in a beam and tested by four-point bending, therefore, the failure mode is a structural failure instead of material failure as is usually the case for TWB [15]. In our study, a shear buckling failure is expected, although the test should be terminated before a full collapse takes place. In many cases, the design of a specific aircraft part is based on failure criteria, fatigue, stiffness, production costs, and environmental impact. However, some of these aspects are not considered in this study, such as fatigue and environmental impact. A design study based on, e.g., fatigue life would have resulted in a different product. Whereas, the objective of this study is to investigate the static strength of the beam with respect to weight reduction; hence, a numerical tool for the structural design of beam-like aircraft parts, like ribs, stringers, and floor beams has been developed. This tool will be combined with the forming processes available for TMB and it will be used to determine the possible advantages that can be obtained by using the TMB concept.

The paper is divided into five parts. After an introduction, "Section 2" deals with the TMB concept and related processes applied in the automotive industry, which may also be suited for aerospace applications. The second part, "Section 3," is focused on a MATLAB code which dimensions and designs the part and calculates the limits of the structural performance of the part/beam. The structural limits are expressed in Von-Mises-based criteria and a safety factor $n_{\mathrm{s}}$. (The floor beam is designed to carry static loads only.) Stiffness is also important when designing an aircraft part. Although the stiffness analysis is not the focus of the model, for completeness, a comparison of the analytical investigation on stiffness with the finite-element method (FEM) and the experimental tests shows that consistent results have been achieved. In the third section, the floor beam of an existing aircraft (of a Fokker 100 see Fig. 1) is selected and discussed as a test case. On the basis of the MATLAB tool, the real floor beam has been re-designed, using the TMB concept and using different materials. In "Section 4," in order to compare both the analytical and numerical predictions with the experimental test results, an additional evaluation using a finiteelement program, ABAQUS 6.5, has been done. Finally, for the validation of the calculations, several tests have been performed. The selected test is a four-point bending test. The results of these experiments are included in this paper 


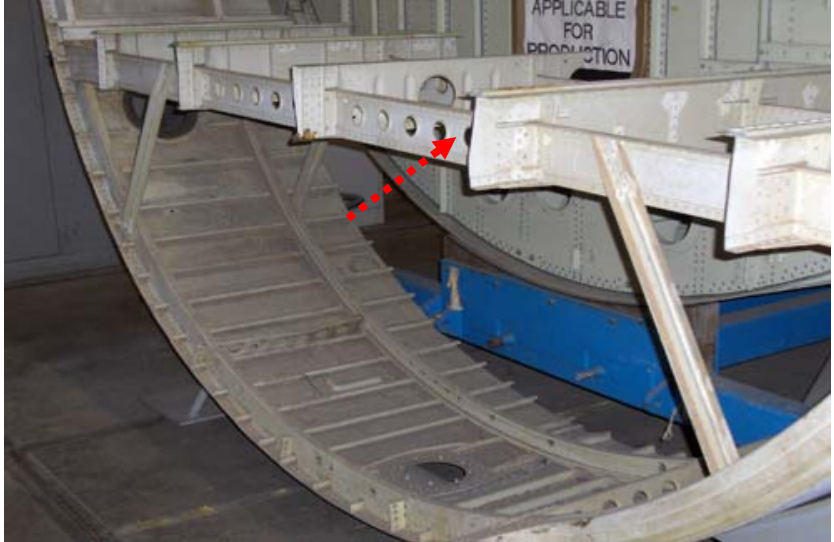

Fig. 1 A floor beam of a Fokker 100 aircraft

in "Section 5." The final discussion results in the conclusion that the application of the TMB concept may result in a $+30 \%$ weight reduction when compared to the reference structure.

\section{The TMB concept and selected materials}

The main characteristic of the TMB concept is that the thickness and/or the metal alloy can be varied and optimized with respect to the design goal.

Tailor-made blanks offer, among others, the following advantages:

- Weight reduction

- Reduction of the number of the parts by integration

- Optimization of the part by definition of tolerances

- Reduction of the manufacturing cost, by less tooling, less parts, less logistics

- Improved corrosion resistance by elimination of overlap joints

- Improved load transfer from one section to the other

For the production of aluminum tailor-made blanks for aerospace applications, several options are available to join two sheets, such as:

- Welding processes, like laser beam welding, TIG welding, or friction stir welding $[5,16]$

- Adhesive bonding

- Local milling/machining of the sheet $[7,16]$

The fabrication of TMB is based on several possibilities of combining sheets: different aluminum alloys and different thicknesses, as presented in Table 1. Considering all the possibilities, six variants of TMB can be derived, as shown in Fig. 2.

Combinations A1 to A3 cover TMBs formed by combining (or milling away) similar materials to obtain thickness variations, while combinations B1 to B3 cover
Table 1 Tailor-made blanks: variations as function of the thickness and type of alloy (see also Fig. 1)

\begin{tabular}{lll}
\hline Type of alloy & Thickness \\
\cline { 2 - 3 } & $t_{\mathrm{I}}=t_{\mathrm{II}}$ & $t_{\mathrm{I}} \neq t_{\mathrm{II}}$ \\
\hline Alloy I=alloy II & Not relevant & Type A1-A3 \\
Alloy I $\neq$ alloy II & Type B1 & Type B2, B3 \\
\hline
\end{tabular}

TMBs made of dissimilar alloys and, in some cases, thickness variation. The sheet thickness selected for the TMB must be representative for aircraft parts. In order to obtain enough information regarding thickness effects, the following sheet thicknesses have been selected: $t 1=$ $0.5 \mathrm{~mm}, t 2=1 \mathrm{~mm}$, and $t 3=2 \mathrm{~mm}$. The minimum thickness of a TMB in this study is $1 \mathrm{~mm}$.

The high-strength aluminum alloys most often used in the aircraft industry and thus considered in this study are: Al-2024-T3, Al-7075-T6, and Al-6061-T6. These materials have been respectively named as M1, M2, and M3.

The adhesive considered in this study is the commercial epoxy resin FM 94 ${ }^{\circledR}$ [17]. This resin is well known in the aircraft industry and has already been adopted for the manufacturing of the latest GLARE aircraft fuselage skin panels [18].

FM $94^{\circledR}$ film adhesive is a $105^{\circ} \mathrm{C}$-service-temperature modified epoxy film adhesive designed for bonding metallic structure. FM $94^{\circledR}$ offers excellent combination of high-temperature performance, toughness, and moisture resistance. For bonding application, e.g., TMB, it provides superior elongation, toughness, and shear strength properties. Regarding strength properties, the FM $94^{\circledR}$ film has shear strength of $20 \mathrm{MPa}$ and shear stiffness of $830 \mathrm{MPa}$, both at room temperature. One of the major reasons of using the adhesive is to carry shear loads. However, as estimated, the maximum shear loads during loading will

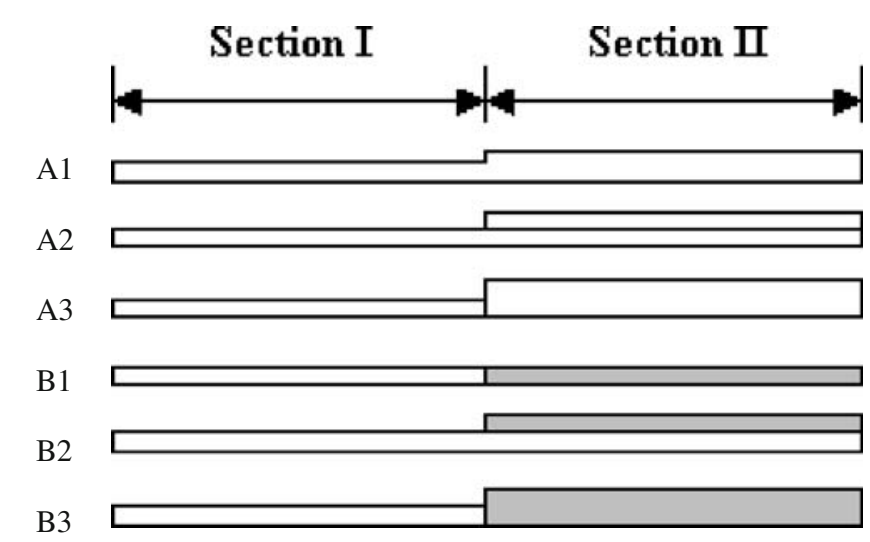

Fig. 2 Overview of TMB variants, variant in thickness and type of alloy 
only be an order of magnitude smaller than the maximum applicable shear stress for the adhesive.

Therefore, failure of the adhesive by shear is not an issue in this research.

In addition, bonding provided by the adhesive guarantees the homogeneity of the bonded parts meaning that there is no influence of the adhesive in the performance of the structure.

There are a few items that need attention regarding the manufacturing processes. One of these is the minimum bending radius. One of the forming processes that are used in this study is the bending process. When this process is applied to a TMB, the bending radius should be different for the two sections of the TMB. During bending, the outside surface of the bend zone is loaded in tension and the inner part in compression (Figs. 3 and 4). Theoretically, assuming ideal bending conditions, the true strain can be calculated as follows [19]:

$\varepsilon_{0}=\ln \frac{(R+t)}{(R+t / 2)}$

A second topic related to forming processes is spring back and its relevant parameters are presented in Fig. 5. In this figure, the bend allowance is the bending length at the neutral axis, which remains constant during bending and after spring back [20].

An important element to consider in the forming of a TMB is the spring-back behavior of both sections, which is affected by the different thicknesses, the radius, and/or mechanical properties.

The problem is most apparent when considering a TMB with different thicknesses. To obtain the same product angle after spring back, such a TMB needs to have different radii and different die angles in both halves. These items become more complicated when thickness steps or different materials in the TMB concept are involved.

The presented concept study could result in an improvement in the performance-to-cost ratio due to the inverse method in forming the parts. The flow diagram below (Fig. 6) shows both processes, the traditional one and TMB route. The TMB concept could improve the cost effectiveness and simplify the assembly process. The first step is an optimization of the thicknesses, using simple numerical methods.

\section{Analytical model}

The model presented in this section is based on the Engineering Bending Theory and it has been implemented in MATLAB 7 code. The scope of this model is to build a tool that gives the best design with respect to sizing and weight reduction. Although the analytical model is able to evaluate a wide range of load cases such as bending moments, torsion moments, and distributed forces combined with several boundary conditions, the final model focuses on four-point bending load case.

The input variables of this MATLAB model are the applied load, the geometry of the beam, and the mechanical/ structural properties of the particular design. The following equation, based on Von Mises stress, has been used as failure criterion

$\sigma_{e q} \times n<\sigma_{y}$,

where $\sigma_{\text {eq }}$ is the maximum Von Mises stress along the beam and $n=1.5$ is the safety factor.

As a result, the analytical model provides the minimum thickness at each section of the beam over the full length, combined with the best selection of materials and fulfilling the Von Mises requirements.

In order to facilitate the inspection, the beam has been divided in three parts/sections called $\mathrm{i}, \mathrm{j}$, and $\mathrm{k}$ and defined by the four bending points.

Regarding this case, it can be considered a typical structural element of an aircraft structure: a Fokker 100 floor beam (Fig. 1), with a length of 1,200 mm, and a "Z" cross section.

This beam has been studied, re-designed (Fig. 7), and manufactured; thus, the final product is shown in Fig. 8 . From the assumption that in our case there are neither axial forces nor torsion moments, the bending theory has been
Fig. 3 Bending angles and bend zone (left); relationship between $\mathrm{R} / \mathrm{t}$ ratio and local thinning (http://www.diegm.uniud.it/ fmiani)
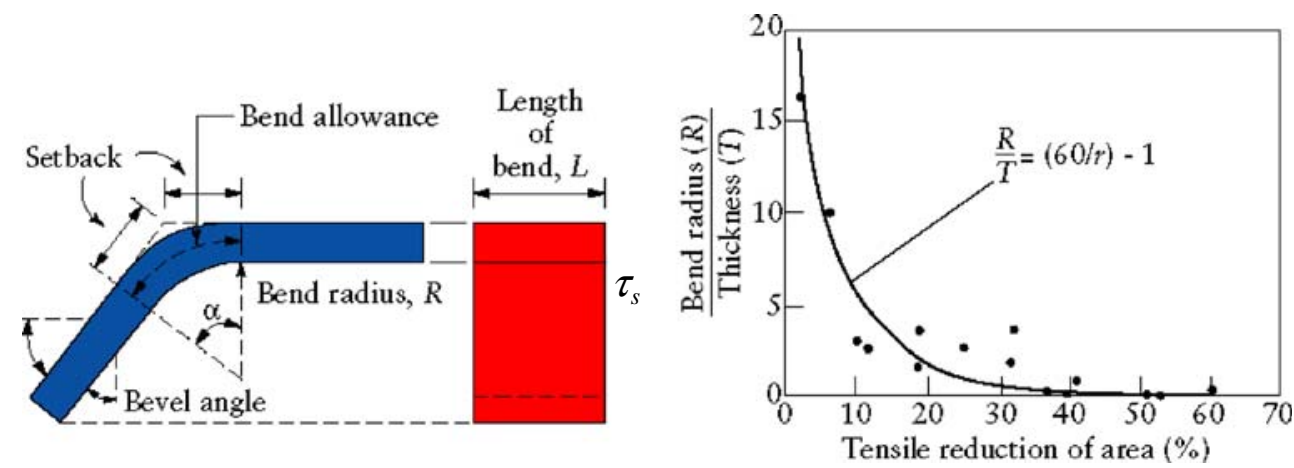
Fig. 4 Crack at the outside of the bend zone (http://www. diegm.uniud.it/fmiani) a

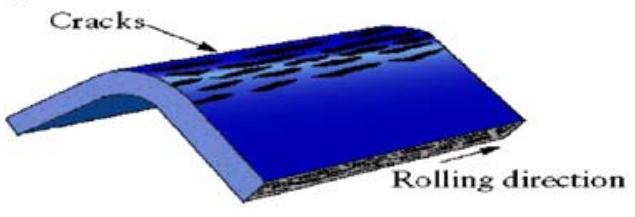

b

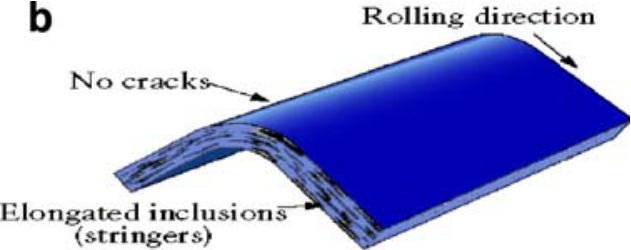

C

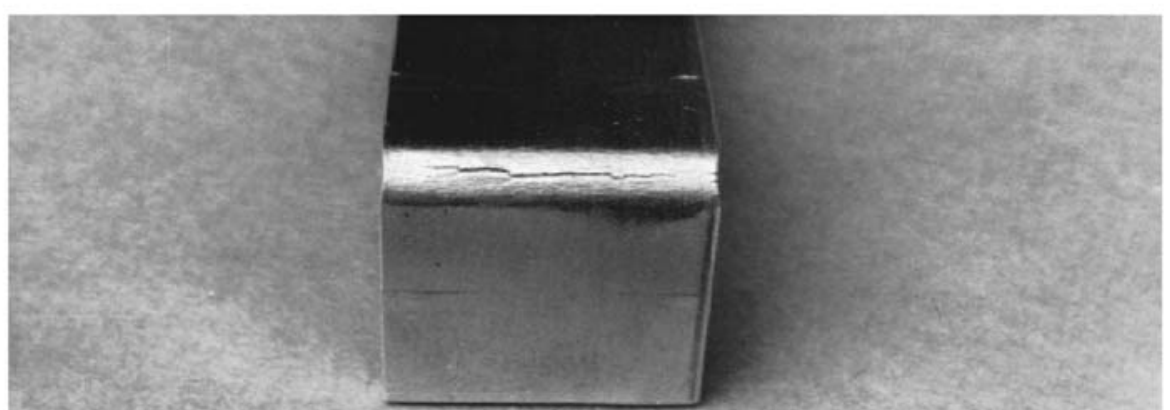

implemented to calculate displacements and deflections. Some functions have been created in order to calculate moments of inertia and finite integration tools like the command "int" have been used to calculate shear flows and bending moments of the beam.

The structure of the computer program is shown in the flow diagram of Fig. 9.

The variables of the model are the thickness, the length, the height. The width of the flanges is constant. The applied forces at each of the four load points have been calculated by considering maneuver loads, pressurization, and passenger weight and seats.

The MATLAB algorithm performs the analysis first by calculating the stresses in the three principal directions then the shear flows and, finally, combining these calculations with the Von Mises failure criterion; the minimum thickness of the beam is given as output. The resulting constant thickness falls in an area with a wide range of possible geometry configurations. Each of these configurations will respect the failure criterion.

The implemented model focuses basically on the structural analysis of the beam, but it does not take into account the properties or behavior of the adhesive layer. In fact, no shear stresses high enough that they could result in de-bonding or peeling out occur during testing and the

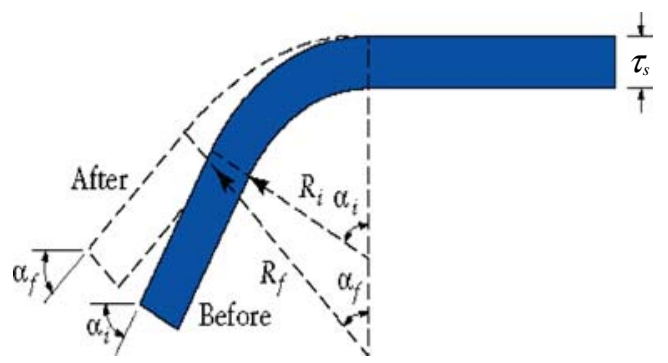

Fig. 5 Definition of parameters of the bending radius (http://www. diegm.uniud.it/fmiani) excellent bonding properties of the thin adhesive layer will not affect the performance of the beam. Therefore, each section of the beam has been considered as monolithic aluminum. Thus, first, the second moment of inertia has been calculated, then the direct stresses using the following formula $([21,22]$ and [23]):

$\sigma_{z}=\left[\begin{array}{l}N / A+M_{x} \times\left(I_{y y} \times y-I_{x y} \times x\right) /\left(I_{x x} \times I_{y y}-I_{x y}^{2}\right) \\ +M_{y} \times\left(I_{x x} \times x-I_{x y} \times y\right) /\left(I_{x x} \times I_{y y}-I_{x y}^{2}\right)\end{array}\right]$

This procedure has been applied over the whole length of the beam and for the most critical points 1,2, and 3 (Fig. 7) of the cross section. Due to the symmetry, only these three points have been considered. Besides, also shear flows $q$ and shear stresses $\tau_{x y}$ have been calculated. These calculations have been done for every generic $z$ section of the beam.

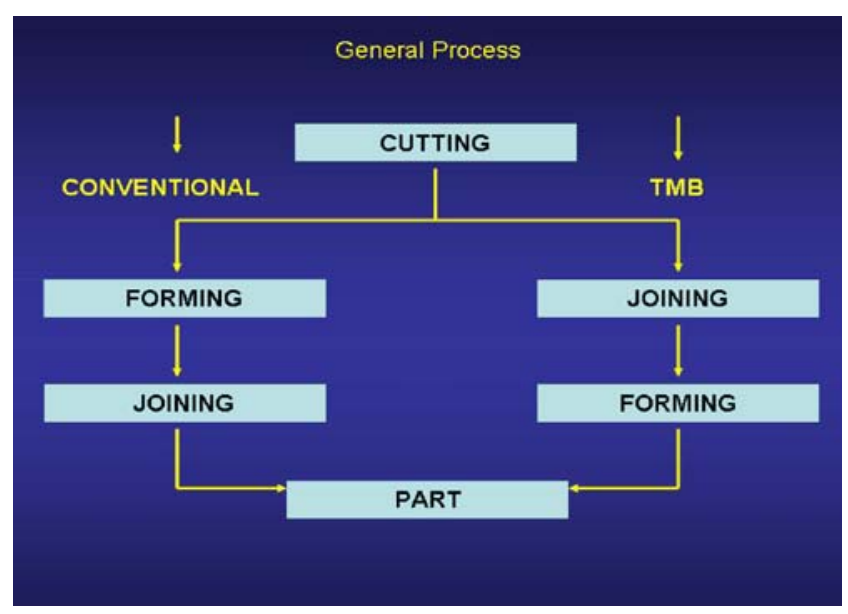

Fig. 6 Flow diagram of the conventional forming process (left) and process using TMB (right) 


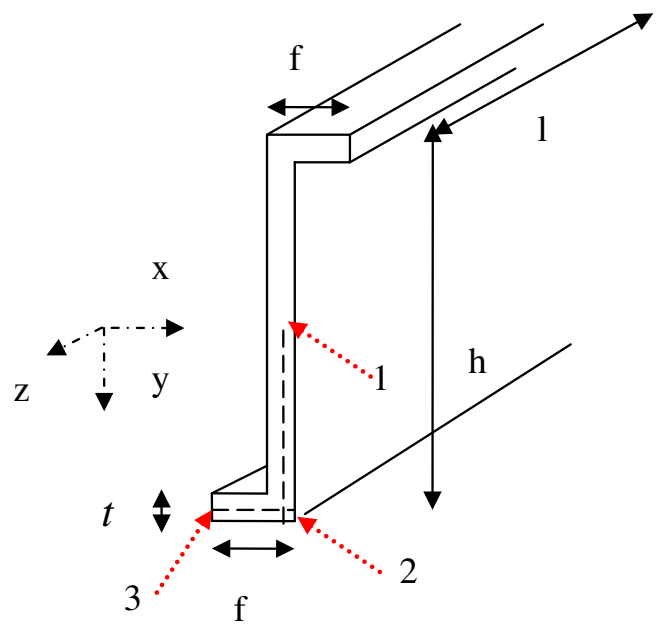

Fig. 7 Cross section of the beam and location of point 2

As an example, the Von Mises criterion has been applied and implemented in MATLAB using the simplified formula $([24,25]$ and [26])

$\sigma_{s}=\sqrt{\sigma_{z}^{2}+3 \tau_{x y}^{2}}$

Subsequently, the safety factor is calculated as:

$M_{1 n 112}=s f_{1} \cdot / \sqrt{\left(\sigma_{z 211}^{2}+3 \times \tau_{x y 211}^{2}\right)} ;$

In the previous MATLAB command line, several parameters have been used:

- $M_{i}=$ is referred to the material used as mentioned in "Section 2";

Fig. 8 Two examples of adhesively bonded TMB beams
- $\quad n_{a, b, c}=$ safety factor at: parts $\mathrm{i}, \mathrm{j}$, or $\mathrm{k}$ along the length, selected thickness $t_{1,2,3}$, evaluation points 1,2 , or 3 ;

- $S_{\mathrm{fi}}=$ is the yield stress of material 1 ;

- $\sigma_{z 211}=$ direct stress at point 2, part of the beam i, selected thickness $t_{1}$;

The boundary conditions have been inserted considering the four-point bending case.

Once the maximum load and boundary conditions have been defined in the four parts of the beam and the safety factor has been defined, the optimum dimensions are given by adapting the thickness in the four sections of the beam to the calculated safety factor $n_{\mathrm{s}}$ such as,

$n_{\mathrm{s}}=\sigma_{y} / \sigma_{\mathrm{s}} \geq 1.5$,

In fact, by introducing the command line "min" in Eq. 3.3, the calculation minimizes the thickness of the beam in all its sections.

The 3D example plot (Fig. 10) represents the calculated safety factor $n_{\mathrm{s}}$ for a given thickness in the three main directions $x, y, z$, at all possible lengths $[0 ; 1,500] \mathrm{mm}$ and heights $[0 ; 200] \mathrm{mm}$. The model will give the optimum thickness along the structure and the whole beam is designed considering the relation $\sigma_{\mathrm{s}} \times n_{\mathrm{s}}<\sigma_{y}$ Concerning the safety factor, this means that failure may occur for $n_{\mathrm{s}}<$ 1.5. In practice, it does not matter where the beam fails, a particular point along the length or over the cross section, because the failure location is not important for this design tool. The MATLAB code calculates the safety factors for beams with constant thickness for all combinations of the height and length of the beams in the specific domain. For each surface, the red line for $n_{\mathrm{s}}=1.5$ divides the domain and

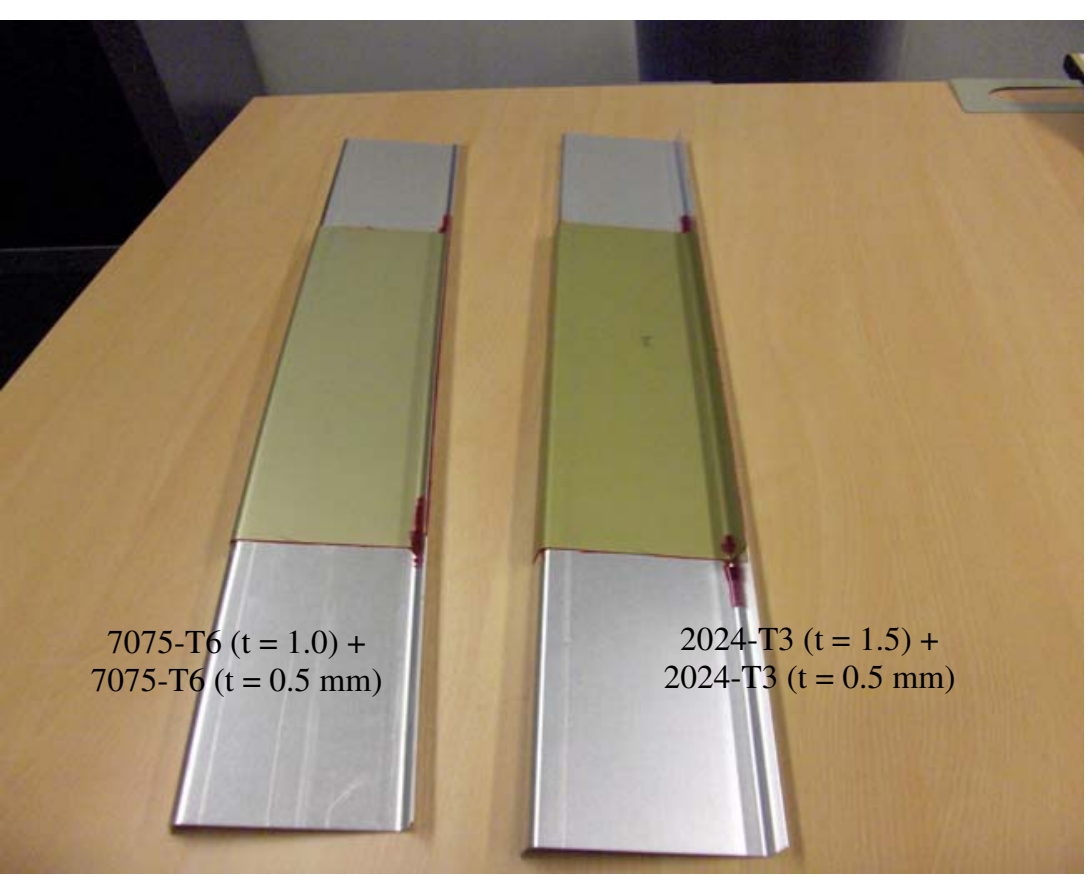




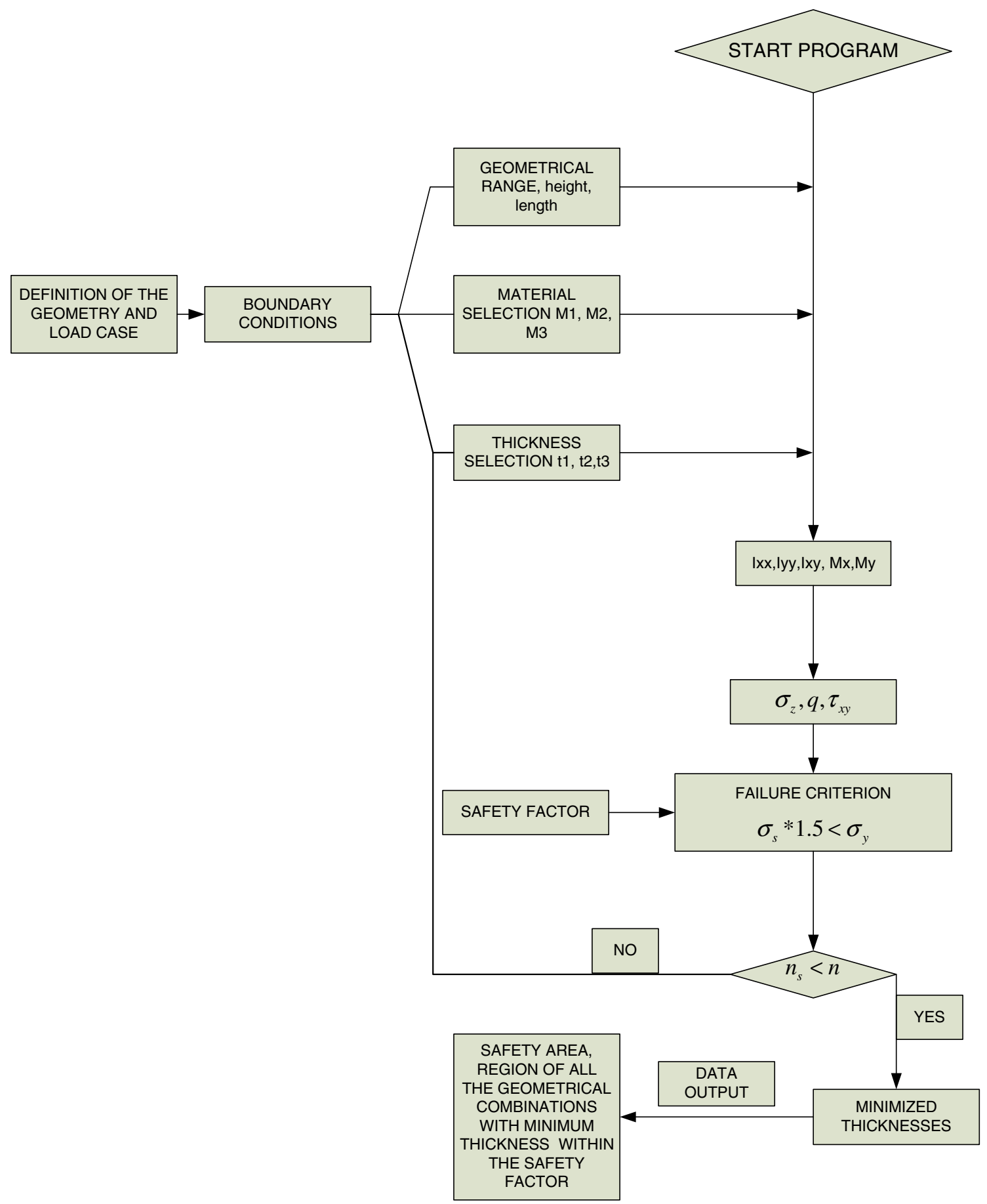

Fig. 9 Flow diagram for the prediction of the safety area within which geometrical limits match the failure criterion

specifies the area that is considered safe (Fig. 10). The three plots on a row represent the same material but for an increasing value of the thickness, i.e., $1,1.5$, and $2 \mathrm{~mm}$. The same thickness related to a different material is represented in the three columns. Therefore, by increasing the thickness, the surface and thereby the applicable combinations of length and height become larger. Note that the shape of these surfaces is related to the four-point bending load case only.

A better overview is obtained by cutting the surface over the marked line. This is done by using the MATLAB command "contour." In this way, we get a plane, a grid region limited by a red line contour, within which we suppose to have a safe beam (Fig. 11). 
Fig. 10 Safety or reserve factor as function of the beam dimensions length and height for different thickness (plots on one row) and different materials (plots in one column)

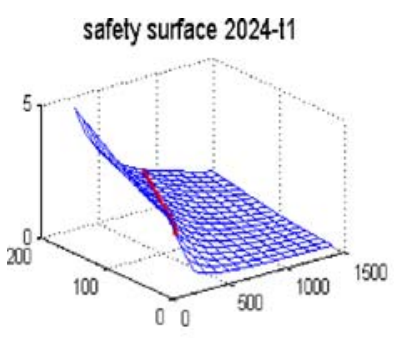

safety surface 6061

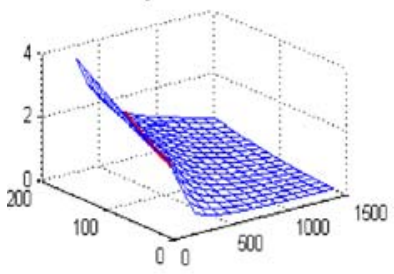

safety surface 7075
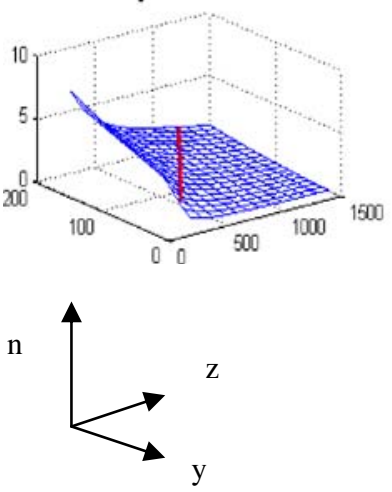

safely surface $2024-12$

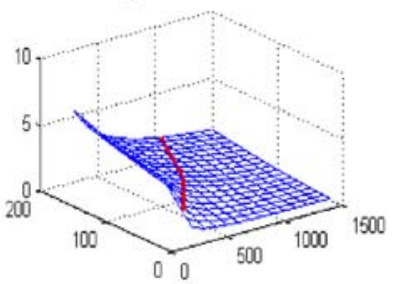

safety surface 6061

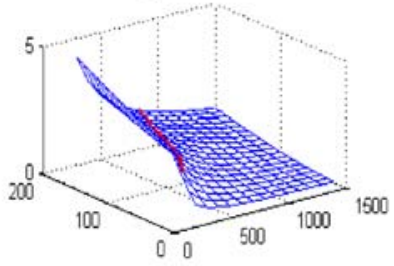

safety surface 7075

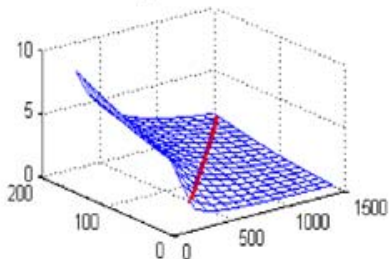

$\mathrm{n}=$ Safety or Reserve factor $[1: 10]$

$\mathrm{z}=$ Length of the beam $[1: 1500 \mathrm{~mm}]$

$\mathrm{y}=$ Height of the beam [1:200 mm]

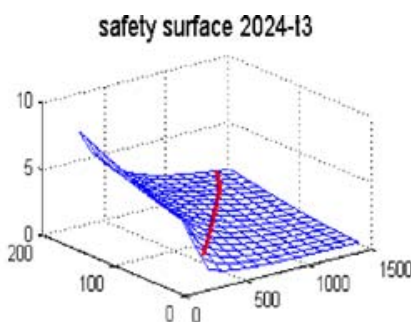

safety surface 6061

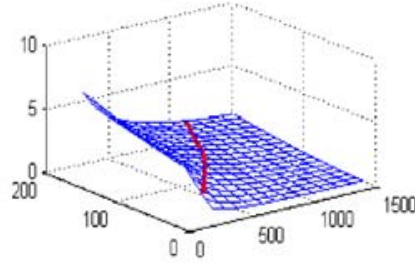

safety surface 7075

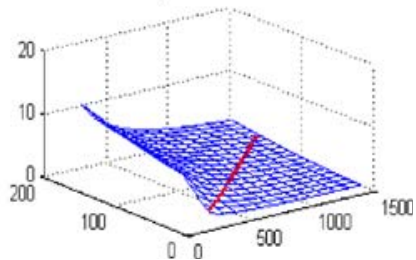

The thickness at this point will be largest, whereas the thickness in other regions can be less.

In reality, however, a gradual change in thickness is unlikely and changes in thickness are stepwise.

Figures 12 and 13 represent the same concept, which is the safety factor based on the Von Mises stress distribution in the longitudinal direction respectively for Al-2024-T3 and for Al-7075-T6. The third selected material, Al-6061T6, has not been considered for this application because of its low-strength properties (relatively to the other alloys). In Fig. 12, the safety factor curve for 2-mm-thick beam of Al2024-T3 matches perfectly with the black line representing the safety factor $n_{\mathrm{s}}=1.5$. Hence, according to the safety factor criterion, the 2-mm-thick beam would be the lower limit (minimum thickness). This is $1.5 \mathrm{~mm}$ for Al-7075-T6 (Fig. 13). However, the thickness can be decreased at both the first and the fourth section of the beam (Figs 12 or 13). For Al-2024-T3 (Fig. 12), the end sections of the beam can have a gradual reduction of the thickness down to $1.5 \mathrm{~mm}$; the central section remains $2 \mathrm{~mm}$. For Al-7075-T6 (Fig. 13), the sections at both ends can have gradual reduction of the thickness down to $1 \mathrm{~mm}$, and the central one should be $1.5 \mathrm{~mm}$.

Another MATLAB program calculates the curve for the thickness-optimized structure at the highest-loaded section. In Fig. 14, the curves show the performance of the beam with the reduction of the thickness; here, the reference material is A1-7075-T6. In reality, during testing, the transition area is not well defined and, due to local bending effects, the thicker part must be extended. On the other hand, the first and the fourth sections of the beam could be further improved, decreasing the thickness until the $n_{\mathrm{s}}$ factor has a value of 1.5.

Clearly, the thickness reduction only regards the most severely loaded point; therefore, in other sections of the beam, like in the flanges, further reductions would be possible.

\section{FEM model}

In order to compare the analytical model with the experimental tests, a third analysis by FEM has been done. The main issue of the FEM is to calculate the maximum Von Mises stress and the strain at point 2 of Fig. 7. The four-point bending test has been simulated by using ABAQUS/CAE ver. 6.5 standard. The beam has been 
Fig. 11 Safety regions (reserve factor $>1.5$ ) as function of the beam dimensions length and height for different thickness (plots on one row) and different materials (plots in one column)
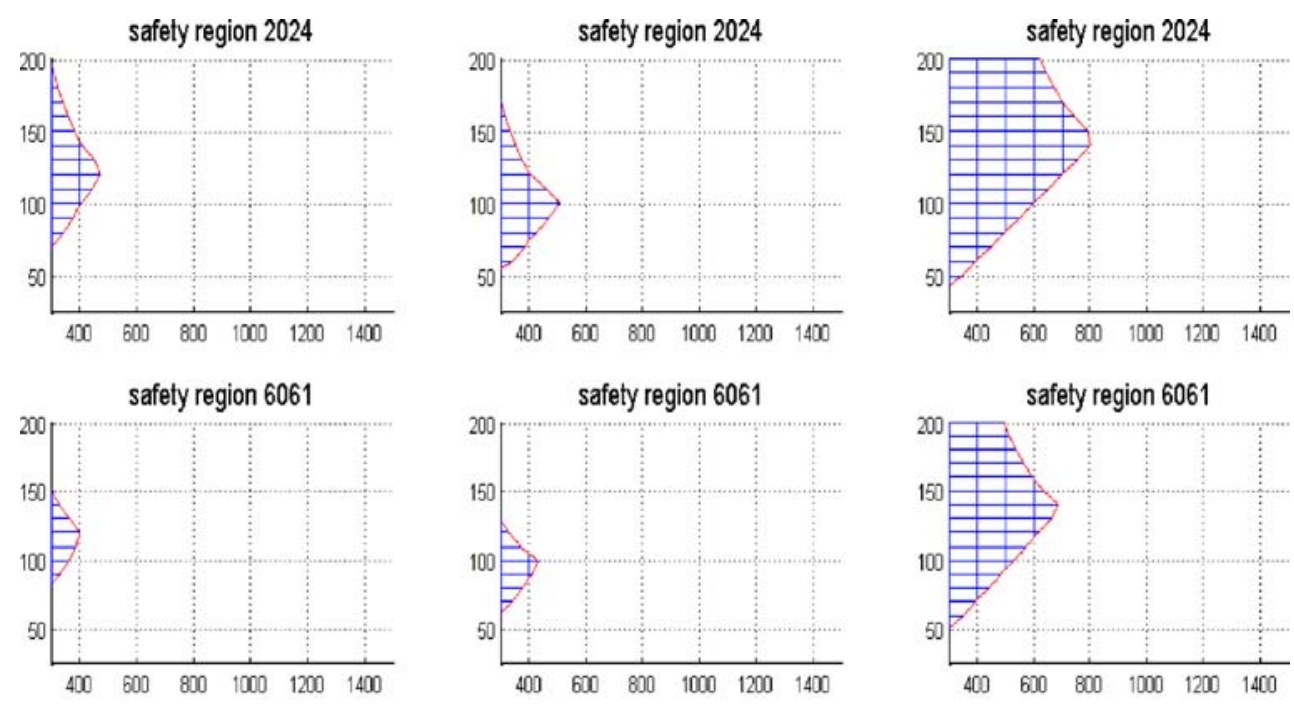

safety region 7075
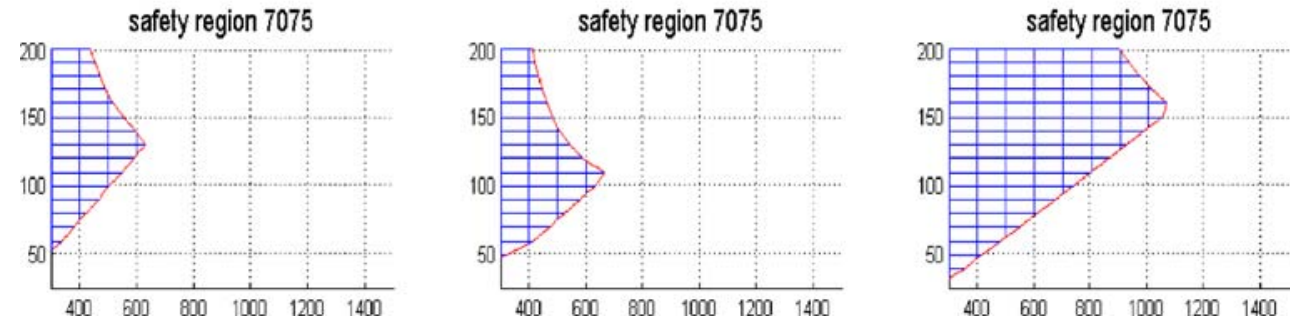

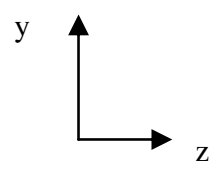

$\mathrm{z}=$ Length of the beam $[1: 1500 \mathrm{~mm}]$

$\mathrm{y}=$ Height of the beam [1:200 $\mathrm{mm}]$

designed using the FEM drawing tools. Geometry and dimensions already introduced in "Section 2" have been used to create the final shape in the FEM model (Fig. 15). In particular, two beams of 1.5 - and $0.5-\mathrm{mm}$ thickness have been designed and then joined together. The bonding area has been created by copying the beam geometry. The adhesive layer has a thickness of $0.15 \mathrm{~mm}$; the properties are taken from [17]; $0.15 \mathrm{~mm}$ is the average thickness of the adhesive layer after curing. The three parts have been assembled together by tying the nodes. Three-dimensional solid (continuum) elements with three translational degrees of freedom and linear hexahedral elements of type C3D8R

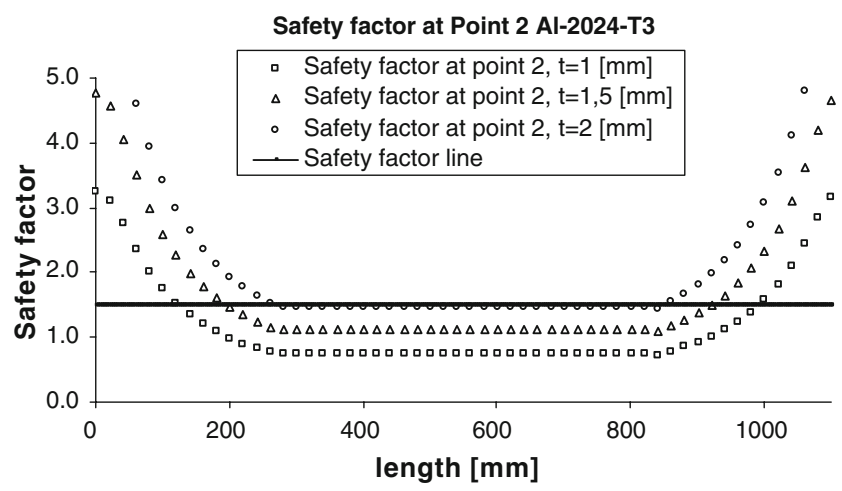

Fig. 12 Point 2, distribution of the safety factor along the Al-2024 beam for three different thicknesses, $t=1,1.5,2 \mathrm{~mm}, L=1,100, H=$ 200

\section{Safety factor at Point 2 Al-7075-T3}

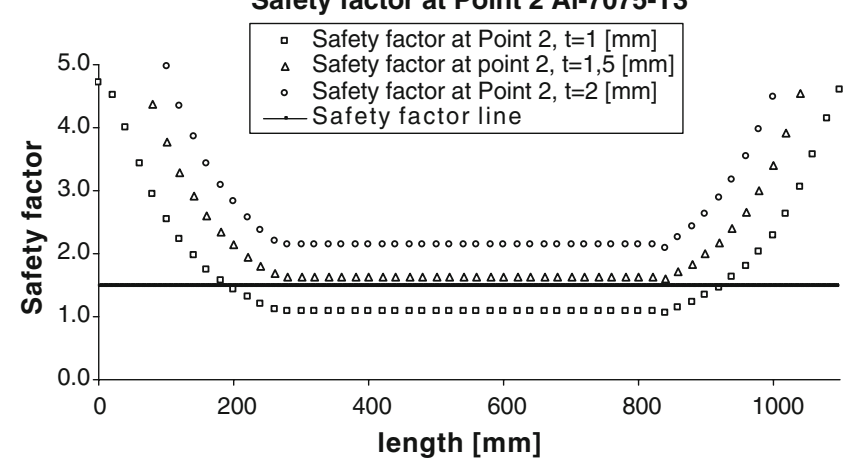

Fig. 13 Point 2, distribution of the safety factor along the Al-7075 beam for three different thicknesses, $t=1,1.5,2 \mathrm{~mm}, L=1,100, H=$ 200 


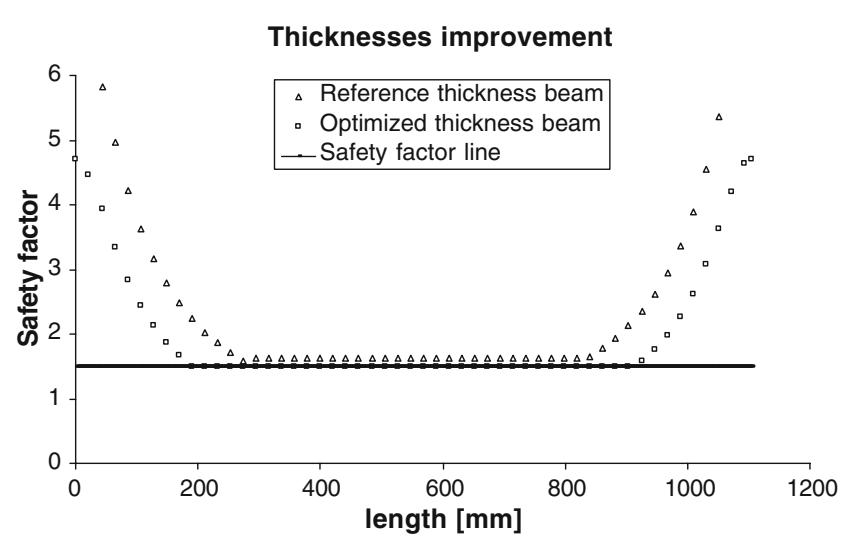

Fig. 14 Point 2, comparison of the distribution of the safety factor between a reference beam with constant thicknesses, triangular symbols, and the improved beam, square symbols

have been used for discretization of the geometries. The reduced-integration scheme with hourglass control has been applied. Those elements have eight nodes and only four integration points. The hexahedral elements have been preferred to the first-order tetrahedral elements because the hexahedral elements provide an equivalent accuracy at less computational cost and have a better convergence rate. Stiffness control is also included in the hourglass option [27]. The computational time of the reduced-integration elements is usually less than the full-integration elements in 3D stress analysis. Generally, the second-order elements can calculate the large stress gradients with high accuracy. However, the second-order elements do not work properly with Von Mises plasticity, which is actually an important parameter in this study. In conclusion, the first-order hexahedral element can provide the best performance regarding accuracy and convergence rate.

Recent studies have shown the possibility of using solid elements in the FEM models of metal sheets [28]. Nevertheless, a significant number of elements should be used so that both the strain and the stress field can be well described. This is a more specific topic when dealing with the bending of metal sheets [28]. The structuring meshing method has been used, meaning that the mesh has been refined were larger stresses and strains were expected. Therefore, the size of the elements has been reduced and consequently the number of bricks has been increased in the bending area where a higher accuracy is required. The model is made of 10,000 brick elements and it is mesh independent. Both explicit and implicit ABAQUS solvers have been used but small differences have been found in the maximum stress level and in the true strain in $E_{33}$ direction. Only a few minutes of difference in the computational time has been found.

Boundary conditions have been selected so that the analysis simulates the actual test conditions. The translational degrees of freedom 3 and 1 have been constrained at external bending points meaning that the beam could not move sideways. Translational degrees of freedom 3, 2, and 1 have been constrained at the load introduction points of the specimens. This boundary condition results in pure bending by leaving the translational degree of freedom 2 free at the two load introduction points in the middle section of the beam. The compression force has been introduced by setting
Fig. $153 \mathrm{D}$ view of the Von Mises stress distribution calculated by the ABAQUS model

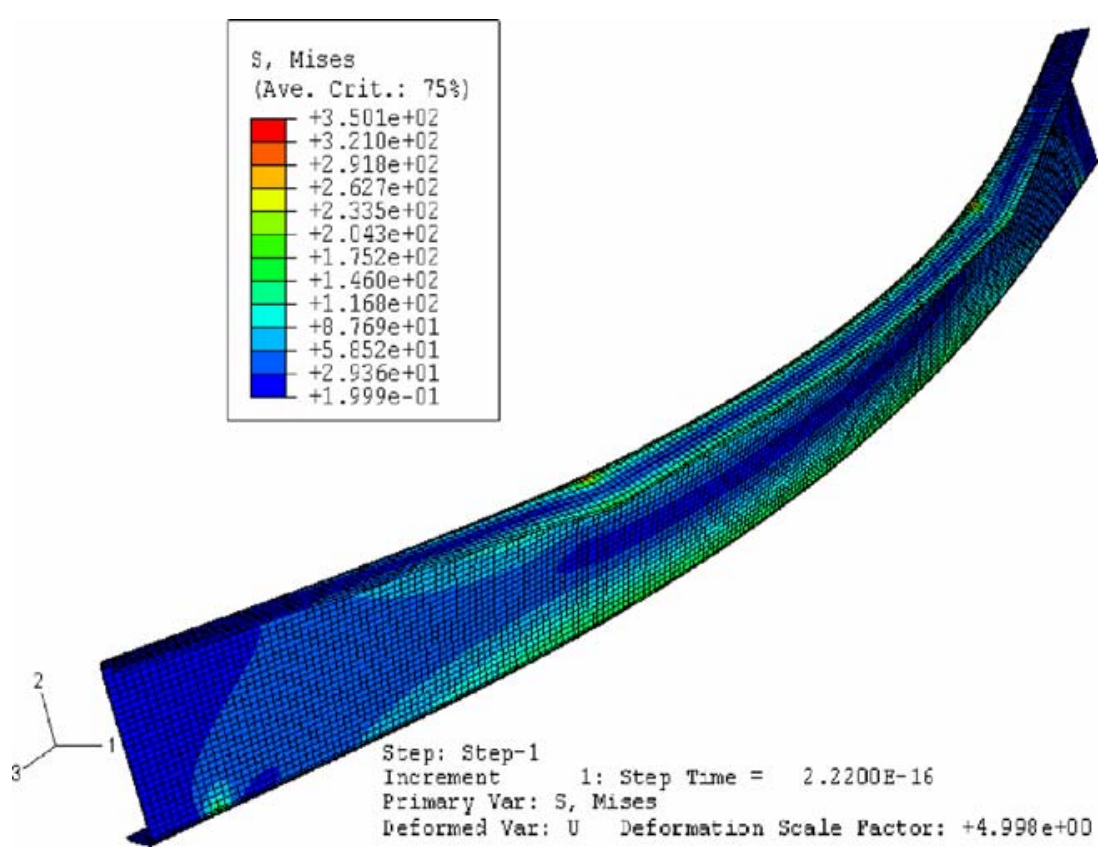


the linear perturbation meaning that a load sequence has been inserted as input. The load sequence is the same as registered in the experimental test. The first experimental test has shown a non-linear behavior of the beam due to, among other reasons, the difficulty to apply the force exactly in the shear center, as it is applied in theory. Besides, when the force increases, the beam starts to move sideways due to shear flows generated in the non-symmetric $Z$ section. This also means that the shear center is moving sideways in that direction, creating secondary-order effects and loads different from the ideal ones. Therefore, it is difficult to expect pure elastic bending of the beam.

Figure 15 shows the outcome of the $3 \mathrm{D}$ analyses. The colors represent the distribution of the Von Mises stresses. In this image, the distribution of the colors shows a symmetric pattern, according to the elastic theory, except for the point of load introduction, where the ABAQUS model also takes local stress effects into account. The applied load is the same as for the analytical model. Thus, every load introducing a point (four-point bending) applies about $3 \mathrm{kN}$. The scale factor of ABAQUS has been increased up to 4.9 to have a clear image of the stress distribution. Plastic deformation has not been considered in this work. Nevertheless, in order to be sure of the correctness of the FE analysis, a nonlinear analysis has also been done. The latter analysis again shows the same behavior for the beam under load; even the same maximum stress level has been reached. Figures 16 and 17 show the distribution of the direct stresses $S_{33}$ in longitudinal direction of the beam and the distribution of the Von Mises stress along the cross section of the bottom flange. The path of the nodes for the $S_{33}$ stresses is shown in the thin red line in the picture.

\section{Test results}

Laboratory tests have been performed to validate the finiteelement analysis (FEA) and the analytical results.

The picture in Fig. 18 shows the results of the laboratory tests. The three different curves of data series represent the applied force versus the strain values (in $z$-direction) measured in the proximity of the point 2 of the beam (Fig. 7).

1. Data series (square symbols) for TMB made of Al-2024

2. Data series (circular symbols) for TMB made of Al-7075

3. Data series (triangular symbols) for a beam with constant thickness (Al-2024)

MATLAB and ABAQUS analyses have shown that the main contribution to the strain is the result of direct stresses in $z$-direction. As can be seen in the plot (Fig. 18), the three curves are close to each other, both in value and in slope. It means that, even with different thickness and different mechanical properties due to different alloys, the beams behave in the same way. The curves present a nonlinear

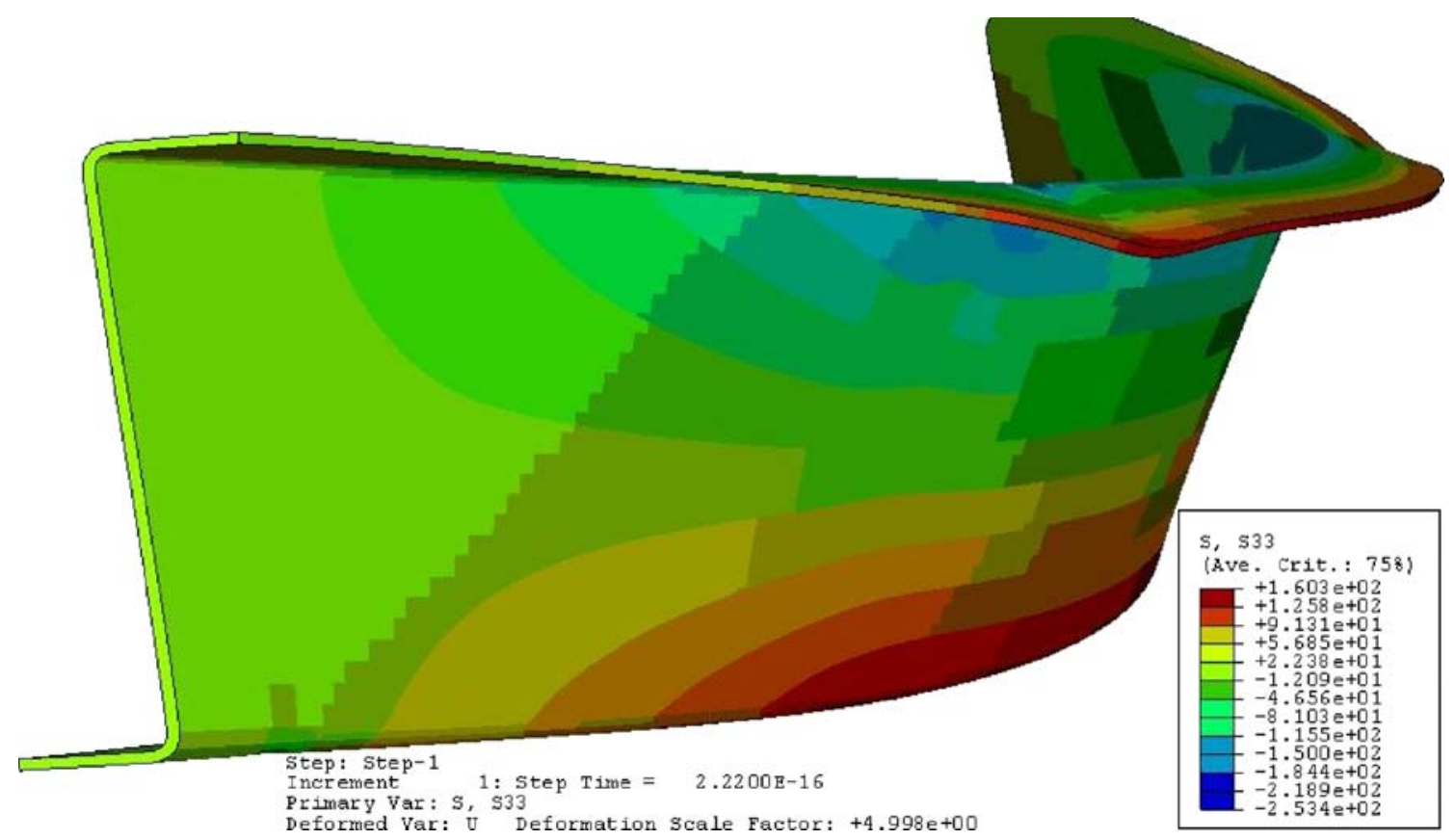

Fig. 16 Flanges, 3D view of the $S_{33}$ direct stress along the beam 

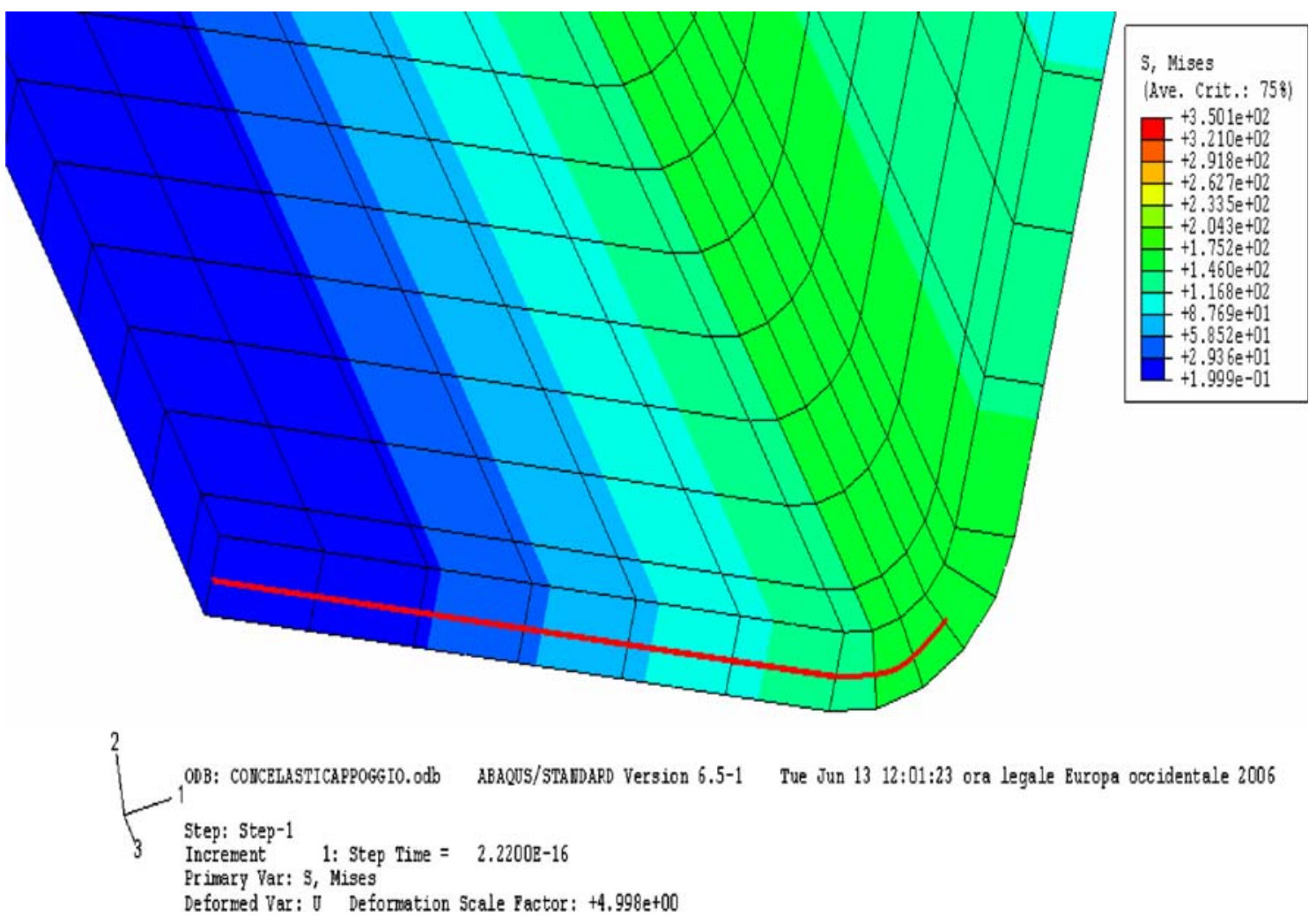

Fig. 17 Detail of a bend radius and node line in the center of the flange

trend due to the applied force. During testing, though, the machine applied the force linearly, but, due to the lateral movement at the load introducing supports on top of the beam (Figs. 19 and 20), the magnitude of the force was not increasing linearly with the strain.

The visible scatter in every curve is also due to this effect. In Fig. 21, there are the differences between the predicted strains in $z$-direction, using the engineering bending theory implemented in MATLAB, and the results of the laboratory tests, represented by the dashed trend line. For a good comparison between the predicted value and the test, only one beam is represented, but similar differences are present for the three beams.

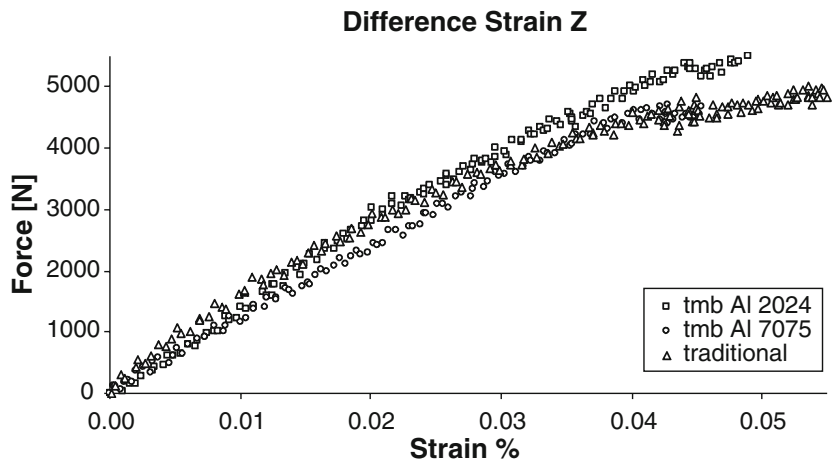

Fig. 18 Force-strain curves for three beams tested: one reference beam (constant thickness) and two TMB concepts
The stiffness behavior of the beam can be evaluated by analyzing the slope of the two curves mentioned above.

$d F / d \varepsilon_{\text {matlab }}=5.12 \mathrm{E}+06$

$d F / d \varepsilon_{\text {test }}=4.00 \mathrm{E}+06$

The difference in value between the two curves is about $20 \%$ and it will be explained later by considering secondary-order effects that occurred during testing.

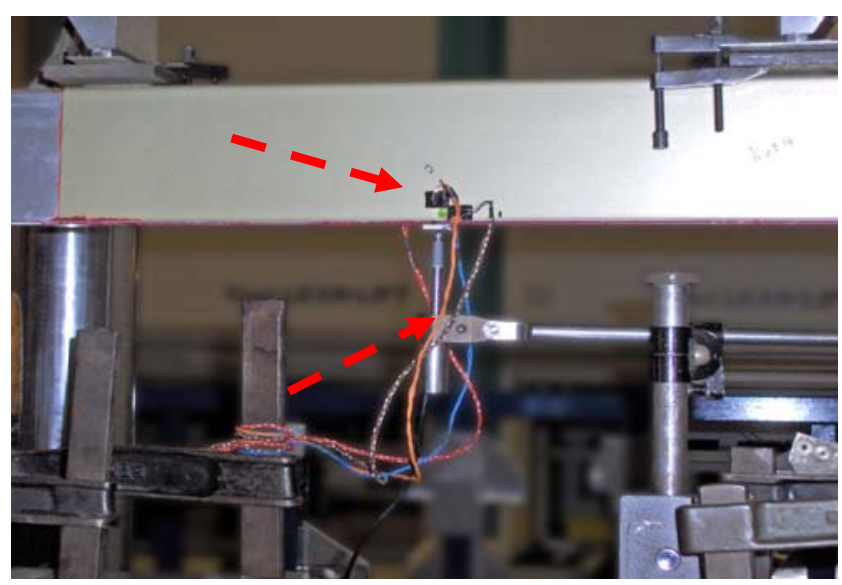

Fig. 19 Test setup for the experimental testing of the beams with the positioning of the strain gauges and the LVDT 


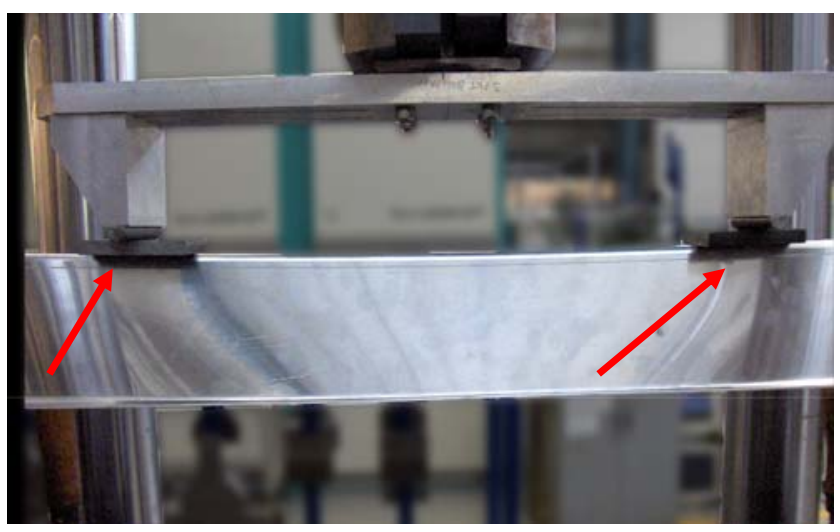

Fig. 20 Test setup with the positions of the load introducing devices and stiff plates

The average ratio between Eqs. 4.2 and 4.1 is about 0.8 .

The data taken from ABAQUS show the value of the strains $\varepsilon_{z}$ named in the FE model as $E_{33}$. In terms of percentage of deflection, $E_{33}$ is $1.85 \%$ at the highest applied load and the force is applied statically. Table 2 shows the magnitude of the direct stress $S_{33}$ and Von Mises stress at point 2 (Fig. 7).

Considering $E_{33}$, the ABAQUS analysis gives values quite close to the ones obtained in the test. This implies that the FE model simulates very well the laboratory test and it is another confirmation that the predicted values by MATLAB, based on the engineering bending theory, are good predictions for this case. From Table 2, which compares the two values of $S_{33}$ and Von Mises stress, it can be concluded that the values are almost coincident. This is also supporting that, as already predicted with MATLAB, the influence of the shear stresses at point 2 does not play an important role in the determination of the total stresses and the maximum applicable force.

Figure 22 shows the difference in the maximum displacement at point 2 of Fig. 7, where the strain gauges were placed. Here, the three lines with symbols are referred to the same beams of the previous plots, like Fig. 18. For

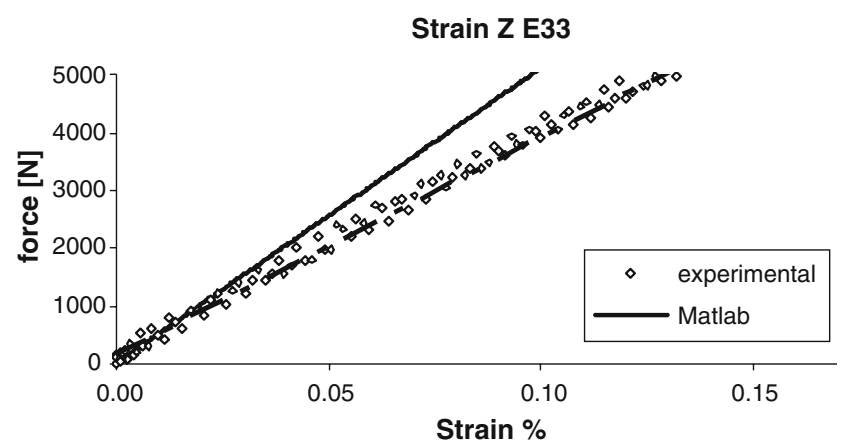

Fig. 21 Comparison between the experimental and the MATLAB results: strains at point 2 in $z$-direction
Table 2 Differences in value between MATLAB and ABAQUS at point 2, see Fig. 7

\begin{tabular}{lllc}
\hline & MATLAB & ABAQUS & Difference [\%] \\
\hline$S_{33}[\mathrm{~Pa}]$ & $1.7105 \mathrm{e}+008$ & $1.5797 \mathrm{e}+008$ & 8 \\
Von Mises $[\mathrm{Pa}]$ & $1.7105 \mathrm{e}+008$ & $1.5796 \mathrm{e}+008$ & 8 \\
\hline
\end{tabular}

the three tests, the load condition was the same, regarding that the setting of the machine was within some margins. These margins are due to the difficulty of centering a nonstable $Z$ section beam. However, the value of the maximum displacement at point 2 (Fig. 7) is almost the same for the three beams, with a difference of about $1 \mathrm{~mm}$, at the same value of the force. Besides, one has to consider that beyond a certain size of the applied force, the setting becomes unstable and the linear variable differential transformer (LVDT) as well. Therefore, it is very difficult to get a repetitive value of the displacement. Figure 23 shows the difference between the predicted value of the displacement and the tested one. The two data series, the square one representing the machine test and the triangular one representing the MATLAB simulation, are obtained using the same applied force.

Also, in this plot, the difference in the displacement between the two curves is about the $10 \%$.

The difference in the slope of the curves obtained by experimental data on one hand and the MATLAB calculation using the Engineering Bending Theory on the other hand can be explained by some nonlinear effects during the experimental tests which are not considered in the elastic theory. In fact, moving the beam downwards beyond a certain displacement, the shear center rotates with respect to its original position due to the instability of the beam. This means that other forces, not predicted by the Engineering Bending Theory, have an influence on the final results.

Table 2 shows that the difference in values of the stresses, taken at point 2, between the analytical model and the ABAQUS simulation is about $13 \mathrm{MPa}$.

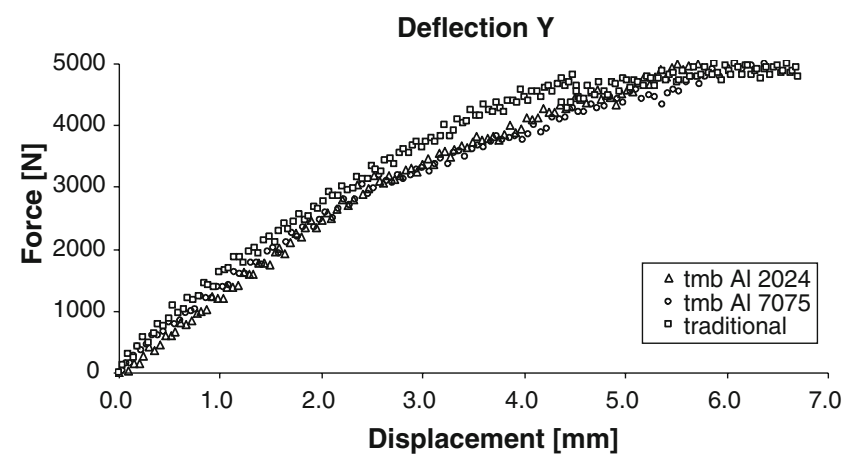

Fig. 22 Comparison of the three beams: displacements in $y$-direction of point 2 


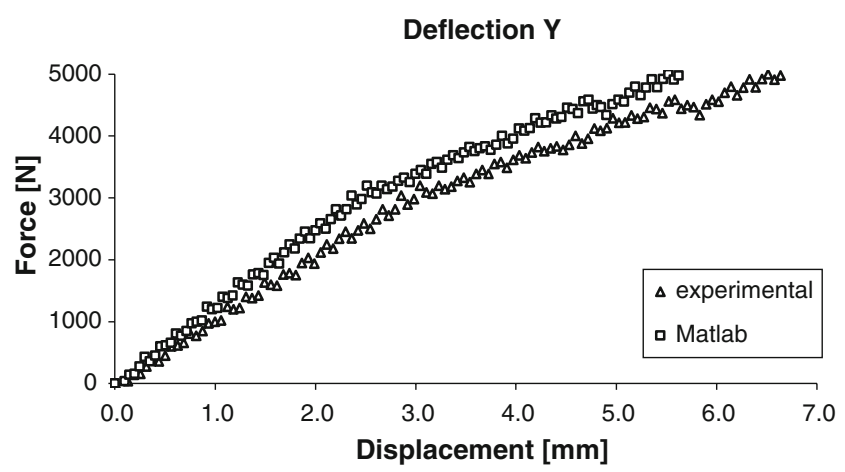

Fig. 23 Comparison between the experimental and calculated beam: displacements at point 2 in $z$-direction

\section{Discussion}

Different approaches to analyze the TMB concept have been used, firstly, a numerical-analytical one, using the MATLAB code, based on the elastic engineering bending theory. The results of this program depend on the part one analyzes and by the applied loads. The analytical model is able to determine the geometry and to predict the performance limit of the specific TMB part, taking the safety factor into account.

Subsequently, laboratory tests have been performed to validate the analytical results and the FEA analysis.

The concept of tailor-made blanks could be a viable option to improve the overall effectiveness of metallic aircraft parts. This improvement may consist of a weight reduction and a reduction of production costs. The weight reductions are related to the "tailor-made" application of the metal alloys and more efficient joints. The reduction of the production costs is related to the reversal of the forming/ joining sequence, resulting in reduction in number of parts, tools, logistic, assembly costs, etc.

This study is focused on the feasibility of tailor-made blanks technology for the aircraft industry. From the results, it is shown that this technology is beneficial for this typical example. The bonding of the beams was at that moment the most efficient, fast, and cheap way to manufacture the TMB. The use of adhesives in aircraft structural parts offers a great advantage in fatigue, when compared to riveting. As already mentioned, three different analysis methods where used for the study. All methods give approximately the same results in terms of stresses and loads the beams can carry. This is a good indication for the correctness of the applied methods. The difference of about $10 \%$ between the different analyses is acceptable, considering the difficulties that were met in the tests. Of course, the $Z$ cross section, considering its deflection during the test, is not the best choice for optimization, just a practical one. Nevertheless, the shape resembles a real floor beam of the fuselage, of the
Table 3 Weight difference between the three beams, the conventional and the two TMB beams

\begin{tabular}{llcc}
\hline & Al-2024 traditional & TMB 2024 & TMB 7075 \\
\hline Weight $(\mathrm{g})$ & 979.6 & 857.1 & 611.4 \\
$\Delta$ Weight [\%] & Reference & -12.5 & -37 \\
\hline
\end{tabular}

Fokker 100. Besides, the shape of the cross section can always be changed in the prediction model that has been built using MATLAB. The obtained results illustrate the capability of the analytical prediction model. Starting from the load the part is supposed to carry and its shape, the model predicts, within a $10 \%$ margin, the best solutions in terms of dimensions, like the length, the height, and the thickness. Furthermore, it gives the possibility to improve the beam by reducing the thickness and still remain within the margin of the safety based on the Von Mises criterion.

The tests show that a TMB beam can carry the same load as a traditional beam. The main difference is of course the advantage in the weight (in this case) and/or the reduction in manufacturing costs. The two TMB beams were made of Al-2024-T3 and Al-7075-T6, respectively. These alloys are well known in the aircraft industry. Between the two alloys, there is a large difference with respect to the static and fatigue properties, but our study was not focused on this aspect. In this study, the TMB beams could carry a load up to $7 \mathrm{kN}$ without any plastic deformation of the beam. Table 3 below shows the advantage in weight using the TMB concept.

The weight reduction is about $12.5 \%$ for Al-2024-T3 and $37 \%$ for Al-7075-T6. The Al-7075-T6 alloy gives the biggest advantage in terms of weight reduction, but this is expected due to the higher yield stress, resulting in a smaller thickness. The reduction in weight is of course the main advantage, but another advantage could be the improved damage tolerance which is related to the bonded structure.

Finally, although the stiffness analysis is not the focus of this research, for completeness, a comparison of the analytical investigation on stiffness with the FEM and the experimental tests shows that consistent results have been achieved (see Table 4). Figure 23 shows the difference in trends between the analytical prediction model based on

Table 4 Strain difference in $y$ - and $z$-direction between the FEM, MATLAB, and the experimental tests

\begin{tabular}{lll}
\hline & Strain $y$-direction $[\mathrm{m}]$ & Strain $z$-direction $[\mathrm{m}]$ \\
\hline ABAQUS & $6.2 \times 10^{-4}$ & $2.04 \times 10^{-3}$ \\
Experimental test & $6.8 \times 10^{-4}$ & $1.85 \times 10^{-3}$ \\
MATLAB & $5.9 \times 10^{-4}$ & $1.93 \times 10^{-3}$ \\
\hline
\end{tabular}


MATLAB and the experimental tests. The trends refer to an optimized thickness beam made of Al-2024-T3 but similar results have been obtained for a beam made of Al-7075-T6.

This study did not consider the economical impact of the concept, for instance in manufacturing costs. Nevertheless, the advantage obtained with the weight reduction satisfied the main objective of this research.

\section{Conclusions and recommendations}

This study has proven the potential of the TMB concept for application in the aircraft industry. The models and the tests used during this study show a reduction in weight of $12.5 \%$ for Al-2024 and 37\% for Al-7075. The results of this study could be further improved by other approaches, like a finiteelement model, having the possibility to change the input, the geometric properties of the part, the loads, and the boundary conditions. The used MATLAB codes can also be improved and the results obtained are only a first step in a much more elaborated work, which may take into account several load cases, fatigue behavior, and/or thermal effects.

In this study, one concept has also been investigated, based on bonding of metal sheets. Other concepts may use welded joints or TMB made by machining. In addition, other production processes should be considered as well to improve the manufacturing of TMB parts, i.e., the rubber forming.

The floor beam analyzed in this study is just an example of how the TMB can be applied in the aircraft industry obtaining advantages in terms of weight reduction. Other parts should be investigated to gain more confidence and experience in the application of the TMB concept.

Open Access This article is distributed under the terms of the Creative Commons Attribution Noncommercial License which permits any noncommercial use, distribution, and reproduction in any medium, provided the original author(s) and source are credited.

\section{References}

1. Rooks B (2001) Tailor welded blanks bring multiple benefits to car design. Assembly Autom 21:323-329. doi:10.1108/ EUM0000000006014

2. Kusuda H, Takasago T, Natsumi F (1997) Formability of tailored blanks. J Mat Proc Tech 71:134-140
3. Automotive Engineering Website (2003) ae-plus.com, December

4. AZoM.com (2003) Audi's new Lamborghini Gallardo with the world's first production ready tailor welded blank.

5. Zadpoor AA, Sinke J, Benedictus R (2008) The mechanical properties and microstructure of friction stir welded tailor-made blanks. Mater Sci Eng A 494:281-290

6. Zadpoor AA, Sinke J, Benedictus R (2008) Mixed-mode analysis of delamination in adhesively bonded tailor-made blanks. In: Proc. of NUMISHEET 2008, Interlaken, Switzerland, pp 421-426

7. Zadpoor AA, Sinke J, Benedictus R (2008) Experimental and numerical study of machined aluminum tailor-made blanks. J Mater Process Technol 200:289-300

8. Miles MP, Decker BJ, Nelson TW (2004) Formability and strength of FSW aluminium sheets.

9. Zadpoor AA, Sinke J, Benedictus R (2008) Finite element modeling and failure prediction of friction stir welded blanks. Mater Des. doi:10.1016/j.matdes.2008.08.018

10. Sato YS, Sugiura Y, Shoji Y, Park SHC, Kokawa H, Ikeda K (2004) Post-weld formability of friction stir welded Al-alloy 5052. Mater Sci Eng A 369:138-143

11. Nagasaka A, Sugimoto KI, Kobayashi M, Makii K, Ikeda S (2004) Press formability YAG-laser welded TRIP/DP tailored blanks. J Phys IV 115:251

12. Chan LC, Cheng CH, Chan SM, Lee TC, Chow CL (2005) Formability analysis of tailor welded blanks of different thickness ratios. J Manuf Sci Eng 127:743-751

13. Chan SM, Chan LC, Lee TC (2003) Tailor welded blanks of different thickness ratios effects on forming limit diagrams. J Mater Process Technol 132:95-101

14. Zhou X (1999) Numerical prediction of spring back in U-channel forming of aluminium tailor welded blanks. M.Sc. thesis, Dept. of Aerospace Engineering, Carlton University.

15. Meinders T, Van den Berg A, Huetink J (2000) Deep drawing simulations of tailored blanks and experimental verification. J Mater Process Technol 103:65-73

16. Zadpoor AA, Sinke J, Benedictus R (2007) Mechanics of tailorwelded blanks: an overview. Key Eng Mater 344:373-382

17. Cytec (2007) FM 94 datasheet. http://www.cytec.com

18. Vlot A, Gunnink JW (2001) Fibre metal laminates, an introduction. Kluwer Academic, Dordrecht

19. Datsko J, Yang CT, Engg J (1960) Industry 82:309

20. Ragab AR, Saleh CHA (2005) Evaluation of bend ability of sheet metals using void coalescence models. Mater Sci Eng A 395:102109

21. Andreaus U (2000) Meccanica della trave. Editrice Esculapio, Bologna

22. Andreaus U (2000) Meccanica dei solidi 3-D. Editrice Esculapio, Bologna

23. Andreaus U (2000) Il Cilindro di Saint-Venant. Editrice Esculapio, Bologna

24. Megson THG (1999) Aircraft structures for engineering students. Butterworth-Heinemann, Oxford

25. Niu MCY (1988) Airframe structural design. Conmilit, Hong Kong

26. Gere JM, Timoshenko SP (1999) Mechanics of materials, 2nd edn. Wiley, Hoboken

27. ABAQUS (2003) Theory manual ver. 6.5. Hibbit, Karlsson \& Sorensen, Pawtucket

28. Zhao KM, Chun BK, Lee JK (2001) Finite element analysis of tailor welded blanks. Fin Elem Anal Des 37:117-130 